\title{
Comparison of Hemoglobin and Hematocrit Concentration between Rh- Hydropic, Non-Hydropic and Control Group; Severe Vs Mild Hydropic Group
}

\author{
Vikas Yadav", Aparna Sharma, Dipika Deka, Vatsla Dadhwal \\ Department of Obstetrics and Gynecology, AIIMS, New Delhi, India
}

DOI: $10.36348 /$ sijog.2020.v03i06.003

| Received: 25.05 .2020 | Accepted: 02.06.2020 | Published: 28.06.2020

*Corresponding author: Vikas Yadav

\section{Abstract}

Introduction: Maternal RBC alloimmunization results from exposure and response to a foreign RBC antigen. Transplacental fetal to maternal hemorrhage is the most common cause of alloimmunization. Rh incompatibility can lead to either fetuses with hydropic features or non hydropic. The precise mechanism leading to the development of hydrops is not certain. All direct fetal sequelae of hemolytic disease relate to the development of anemia. In general, the fetus tolerates mild to moderate anemia well. However, metabolic complications develop as the anemia worsens. Because the RBC is the principal fetal buffer, a metabolic acidemia with hyperlactatemia develops in fetuses with severe anemia. Objective: To compare the difference in mean hemoglobin and hematocrit concentration between Rh-hydropic, non hydropic and control group and further based on severity of hydrops. Methods: A Total of 40 pregnant patients were enrolled which included 10 hydropic fetuses of $\mathrm{Rh}$ isoimmunised mothers, 10 non hydropic fetuses of $\mathrm{Rh}$ isoimmunized mothers. Control group included $18 \mathrm{Rh}$ positive women without any fetal complication and 2 fetuses in women undergoing cordocentesis. Blood sampling was done at time of intrauterine transfusion and sent for estimation of hemoglobin and hematocrit in fetal blood. Pregnancies were followed up till delivery and fetal outcome noted. Result: Mean values of haemoglobin in hydrops group are $4.54 \mathrm{~g} \%$, as compared to $6.65 \mathrm{~g} \%$ and $14.26 \mathrm{~g} \%$ in non-hydrops and control group. Mean haematocrit in hydropic group is $13.91 \%$ as compared to $20.25 \%$ and $43.51 \%$ in non hydropic and control group. The mean haemoglobin concentration in mild hydrops was $5.17 \mathrm{~g} \%$ as compared to $2.7 \mathrm{~g} \%$ in severe hydrops. Conclusion: There was severe hemoglobin and hematocrit deficit in hydropic fetuses as compared to non hydropic and normal fetuses matched for the gestation age. Thus severity of anemia can be considered a strong marker for development of hydrops in $\mathrm{Rh}$ isoimmunized fetuses.

Keywords: Hemoglobin Hematocrit Mild Hydropic Group isoimmunized.

Copyright @ 2020: This is an open-access article distributed under the terms of the Creative Commons Attribution license which permits unrestricted use, distribution, and reproduction in any medium for non-commercial use (NonCommercial, or CC-BY-NC) provided the original author and source are credited.

\section{INTRODUCTION}

$\mathrm{Rh}$ incompatibility refers to a condition developing in an $\mathrm{Rh}$ negative mother carrying an $\mathrm{Rh}$ positive fetus, due to maternal anti $\mathrm{Rh}$ antibodies; resulting in serious, sometimes life-threatening condition in the fetus- anemia, jaundice, leading to kernicterus and even death. Rh sensitization occurs in approximately 1 per 1000 births to women who are Rh negative [1]. Levine and coworkers identified that the rhesus (Rh) antibodies on the RBCs of affected but not unaffected neonates was the cause of the anemia [2]. In 1961, hemolytic anemia became the first treatable fetal disease after Sir William Liley characterized its natural history and then successfully transfused affected fetuses intraperitonealy with adult RBCs [3]. The incidence of $\mathrm{Rh}$-negative individuals varies by race [4]. The vast majority $(85 \%)$ of individuals are considered $\mathrm{Rh}$ positive. Rh sensitization occurs in approximately 1 per 1000 births to women who are $\mathrm{Rh}$ negative [5].

All direct fetal sequelae of hemolytic disease relate to the development of anemia. However, metabolic complications develop as the anemia worsens [6]. Presently ultrasound is the only tool being used for finding the severity of hydrops and cardiac failure [7]. If MCA PSV value is $>1.55 \mathrm{MoM}$ intrauterine 
transfusion is done, also intrauterine transfusion is done in a hydropic fetus at the time of detection [8].

All direct fetal sequelae of hemolytic disease relate to the development of anemia [9]. The present study has therefore been planned to find the hemoglobin and hematocrit deficit based on severity of $\mathrm{Rh}$-isoimmunization.

\section{MATERIALS AND METHODS Study population}

This prospective study was conducted in the Department of Obstetrics and Gynecology at AIIMS, DELHI from june 2014 to july 2016. Exclusion criteria were. Multiple pregnancy, patients with medical disorders, fetuses in whom cordocentesis for genetic indication detected chromosomal anomaly .Ethical Clearance was obtained from the institutional ethical committee. Informed written Consent was taken from the women.

\section{Examination and procedure}

$\mathrm{Rh}$ isoimmunized patients whose MCA PSV values were $>1.5 \mathrm{MoM}$ were given intrauterine transfusion of doubly irradiated and centrifuged blood. They were followed up by ultrasound and MCA-PSV, and subsequent intrauterine transfusions performed when indicated as per Institute protocol of management of Rh-isoimmunised pregnancies. Severity of hydrops was quantitated based on Ascetic rim measured at level of hepatic vein in transverse view into $4-6 \mathrm{~mm}$ (mild) and $\geq 6 \mathrm{~mm}$ (severe).

\section{STATISTICAL ANALYSIS}

The data were entered in Microsoft Excel spread sheet and analysed using statistical product service solutions (SPSS) software IBM version 19.0. Mean values compared using analysis of variance (ANOVA). Frequency distributions were compared using Chi-square/Fisher's exact test as appropriate. A probability value of $\mathrm{p}$ value of $<0.05$ was considered for statistical significance.

\section{RESULTS}

A total of forty pregnant women attending the outpatient department of department of Obstetrics and Gynaecology, All India Institute of Medical Sciences (AIIMS) New Delhi, were enrolled in the study it included 10 hydropic fetuses of $\mathrm{Rh}$ isoimmunised mothers, 10 non hydropic fetuses of $\mathrm{Rh}$ isoimmunized mothers, Control group included $18 \mathrm{Rh}$ positive women without any fetal complication or anomaly who came with preterm labor and delivered, and 2 fetuses in women undergoing cordocentesis for genetic indication at 23 and 26 weeks period of gestation but were normal.

The mean age group of the patients was 29.60 years and was similar in non hydropic, hydropic group and in control Group. There was significant difference between hydrops, non-hydrops and control groups with respect to parity. All the patients in hydropic and non hydropic group were multigravida. mean gestation age was 26.01 weeks (SD 3.59, range 21.2-32.4) in hydropic group as compared to 28.3 weeks (SD3.6,range 23.7-34.8) in non hydropic and 31.7 weeks (SD 3.2,range 23.8-36.5) in control group and was comparable.

There were 2 with fetal ascitic rim more than 6 $\mathrm{mm}$ (severe hydrops), whereas 8 patients had fetal ascitic rim between 4-6 $\mathrm{mm}$ (mild hydrops).number of patient based on severity of hydrops in table 1 .

Mean total number of IUTs received by hydrops and non-hydrops was 4.90 and 3.20 respectively. $P$ value was significant $(p=0.024)$

Mean values of haemoglobin in hydrops group are $4.54 \mathrm{~g} \%$, as compared to $6.65 \mathrm{~g} \%$ and $14.26 \mathrm{~g} \%$ in non-hydrops and control group. $\mathrm{p}$ value was significant $<0.01$. Mean hemoglobin and hematocrit concentration in cord blood at first intrauterine transfusion in relation to presence/absence of fetal hydrops given in table 2 .

Mean haematocrit in hydropic group is $13.91 \%$ as compared to $20.25 \%$ and $43.51 \%$ in non hydropic and control group. Hemoglobin and hematocrit concentration in cord blood at first intrauterine transfusion in relation to period of gestation and presence/absence of fetal hydrops in table 3 and table 4 . Severity of hydrops was quantitated based on ascitic rim into 4-6 $\mathrm{mm}$ (mild) and $\geq 6 \mathrm{~mm}$ (severe). The mean haemoglobin concentration in mild hydrops was $5.17 \mathrm{~g}$ $\%$ as compared to $2.7 \mathrm{~g} \%$ in severe hydrops. $\mathrm{p}$ value was significant $<0.01$.

The mean haematocrit concentration in mild hydrops was $15.37 \%$ as compared to $7.6 \%$ in severe hydrops. There was significant difference in mean haemoglobin and haematocrit concentration between two groups. $\mathrm{P}$ value was significant $<0.01$. Mean hemoglobin and hematocrit in cord blood sampling at first intrauterine transfusion in relation to severity of fetal hydrops in table 5. In the present study $90 \%$ of non hydropic fetuses delivered after 34 weeks POG whereas $30 \%$ and $50 \%$ of control and hydropic fetuses delivered after 34 weeks POG. It was statistically significant.

In the present study in control group 14 women in preterm labor delivered vaginally as compared to $2 / 10$ in hydropic and $3 / 10$ in non hydropic group. 6 in control group underwent caesarean section for maternal/ fetal indication most common being fetal distress. $8 / 10$ in hydropic group and $7 / 10$ in non hydropic group underwent cesarean section, most common indication being fetal anemia with poor biophysical profile. $3 / 10$ in non hydropic group, $1 / 10$ in hydropic group deliverd after 36 weeks POG. 
There was no significant difference in mean cord blood PCV between hydropic and non hydropic group according to period of gestation at delivery. Mean cord blood PCV in hydropic group was $42.75 \%$ as compared to $50 \%$ in non hydropic group.

Table-1: Number of patients according to severity of hydrops

\begin{tabular}{|l|l|}
\hline Ascitic rim (mm) at time of first IUT & Number of fetuses \\
\hline $4-6$ (mild hydrops) & 8 \\
\hline$\geq 6$ (severe hydrops) & 2 \\
\hline
\end{tabular}

Table-2: Mean hemoglobin and hematocrit concentration in cord blood at first intrauterine transfusion in relation to presence/absence of fetal hydrops

\begin{tabular}{|l|l|l|l|}
\hline Mean (SD) & $\begin{array}{l}\text { Hydrops } \\
(\mathbf{n = 1 0})\end{array}$ & $\begin{array}{l}\text { Non hydrops } \\
(\mathbf{n = 1 0})\end{array}$ & $\begin{array}{l}\text { Controls } \\
(\mathbf{n = 2 0})\end{array}$ \\
\hline $\mathrm{Hb}(\mathrm{g} / \mathrm{dl})$ & $4.54(1.24)$ & $6.65(1.47)$ & $14.26(1.26)$ \\
\hline $\mathrm{Hct}(\%)$ & $13.91(3.58)$ & $20.25(4.50)$ & $43.51(3.98)$ \\
\hline
\end{tabular}

Table-3: Hemoglobin concentration in cord blood at first intrauterine transfusion in relation to period of gestation and presence/absence of fetal hydrops

\begin{tabular}{|l|l|l|l|l|}
\hline Period of gestation (weeks) & $\begin{array}{l}\text { Hydrops } \\
\text { Mean hb }(\mathbf{S D}) \\
\text { (g/dl) }\end{array}$ & $\begin{array}{l}\text { Non hydrops } \\
\text { Mean hb }(\mathbf{S D}) \\
\text { (g/dl) }\end{array}$ & $\begin{array}{l}\text { Control } \\
\text { Mean hb }(\mathbf{S D}) \\
(\mathbf{g} / \mathbf{d l})\end{array}$ & P value \\
\hline $20-26 \mathrm{WK}$ & $4.81(1.23)$ & $5.90(1.25)$ & 16.40 & $<0.01$ \\
\hline $26^{+1}-32 \mathrm{WK}$ & $3.90(1.25)$ & $6.76(1.56)$ & $14.68(0.99)$ & $<0.01$ \\
\hline $32^{+1}-38 \mathrm{WK}$ & 5.80 & 8.20 & $13.66(1.18)$ & $<0.01$ \\
\hline
\end{tabular}

Table-4: Hematocrit in cord blood sampling at first intrauterine transfusion in relation to period of gestation and presence/ absence of fetal hydrops

\begin{tabular}{|l|l|l|l|l|}
\hline $\begin{array}{l}\text { Period of gestation } \\
\text { (weeks) }\end{array}$ & $\begin{array}{l}\text { Hydrops } \\
\text { Mean het (SD) } \\
(\boldsymbol{\%})\end{array}$ & $\begin{array}{l}\text { Non hydrops } \\
\text { Mean het (SD) } \\
(\boldsymbol{\%})\end{array}$ & $\begin{array}{l}\text { Control } \\
\text { Mean hct (SD) } \\
(\boldsymbol{\%})\end{array}$ & P value \\
\hline $20-26 \mathrm{WK}$ & $14.38(3.87)$ & $17.53(3.25)$ & 49.20 & $<0.01$ \\
\hline $26^{+1}-32 \mathrm{WK}$ & $11.93(2.99)$ & $20.85(4.83)$ & $44.33(3.22)$ & $<0.01$ \\
\hline $32^{+1}-38 \mathrm{WK}$ & 17.0 & 24.80 & $42.20(4.24)$ & $<0.01$ \\
\hline
\end{tabular}

Table-5: Mean hemoglobin and hematocrit in cord blood sampling at first intrauterine transfusion in relation to severity of fetal hydrops

\begin{tabular}{|l|l|l|l|}
\hline $\begin{array}{l}\text { Ascitic rim } \\
\text { (MM) }\end{array}$ & $\begin{array}{l}\text { Hb } \\
\text { (g/dl) } \\
\text { Mean (SD) }\end{array}$ & $\begin{array}{l}\text { Hct } \\
(\%)\end{array}$ & P value \\
Mean (SD) & \\
\hline $4-6(\mathrm{n}=8)$ & $5.12(1.20)$ & $15.37(3.42)$ & \\
\hline$\geq 6(\mathrm{n}=2)$ & $2.7(0.98)$ & $7.6(2.64)$ & $\mathrm{P}<0.05 \mathrm{sig}$ \\
\hline
\end{tabular}

\section{DISCUSSION}

$\mathrm{Rh}$ incompatibility is a condition developing in a $\mathrm{Rh}$ negative mother carrying a $\mathrm{Rh}$ positive fetus due to maternal anti $\mathrm{Rh}$ antibodies resulting in a serious, sometimes life-threatening reaction in the fetus. Current concepts on the pathophysiology of hydrops in fetal anemia include myocardial failure, high output cardiac failure, reduced plasma colloid oncotic pressure, increased capillary permeability and obstruction of venous and lymphatic flow [10]. Very often hydrops fetalis resolve after varying range of time or even remain unresolved [11].

There remains lacunae and need for knowing biochemical abnormalities in relation to severity of anemia leading to cardiac failure and late or non- resolution of hydrops. Comparing the difference in hemoglobin and hematocrit will help in predicting the development of hydrops/prognosis of hydrops/resolution of hydrops, or even change in fetal therapy

The present study attempted to investigate the deficit in hemoglobin and hematocrit concentration in $\mathrm{Rh}$ isoimmunized fetus and based on severity of hydrops.

In a study by Nicolaides $\mathrm{KH}$ et al. the haemoglobin was measured in fetal blood from 154 red cell isoimmunised pregnancies from 17 to 36 weeks' gestation. In 48 fetuses with ultrasound features of hydrops the haemoglobin was 7-10 g/dl below the 
normal mean for gestation. Into mild (haemoglobin deficit less than $2 \mathrm{~g} / \mathrm{dl}$ ), moderate (deficit 2-7 g/dl), and severe (deficit greater than $7 \mathrm{~g} / \mathrm{dl})[12]$.

In another study done by Warenski JC et al. all fetuses with sonographic evidence of hydrops had hemoglobin of $3.8 \mathrm{gm} / \mathrm{dl}$ or less, whereas all but one of those without hydrops had a haemoglobin greater than $4.0 \mathrm{gm} / \mathrm{dl}[13]$.

Strength of our study was that we categorized severity of hydrops based on ascitic rim and compared the difference in hemoglobin and hematocrit concentration between these two groups. We found a significant difference in hemoglobin and hematocrit concentration between the $\mathrm{Rh}$ isoimmunized and hydrops group and the difference was significant even between mild and severe hydrops. Limitation of our study was small sample size.

\section{CONCLUSION}

This study is one of the few studies which compared the hemoglobin and hematocrit concentration between $\mathrm{Rh}$ isoimunized non hydropic and hydropic group when compared with controls. There was significant difference between mild and severe hydrops. There was severe hemoglobin and hematocrit deficit in hydropic fetuses as compared to non hydropic and normal fetuses matched for the gestation age.

\section{REFERENCES}

1. Sullivan, J. F., Peckham, N. H., \& Jennings, E. R. (1967). Rh isoimmunization: Its incidence, timing, and relationship to fetal-maternal hemorrhage. American Journal of Obstetrics \& Gynecology, 98(6), 877-880.

2. Liley, A.W. (1961). Liquor amnii analysis in management of pregnancy complicated by rhesus sensitization; Am J Obstet Gynecol, 82:135-39.

3. Liley, A.W.(1963). Errors in the assessment of hemolytic disease from amniotic fluid. Am J Obstet Gynecol; 86:485-494.

4. Trainor, B., Tubman. (2006). The emerging pattern of hydrops fetalis--incidence, aetiology and management; Ulster Med J, 75:185-6
5. Snyder, E.L.(1998). Prevention of hemolytic disease of the newborn due to anti-D. Prenatal/perinatal testing and $\mathrm{Rh}$ immune globulin administration; Am Assoc Blood Banks, 1:321-35

6. Nicolini, U., Nicolaidis, P., Tannirandorn, Y., Fisk, N. M., Nasrat, H., \& Rodeck, C. H. (1991). Fetal liver dysfunction in $\mathrm{Rh}$ alloimmunization. BJOG: An International Journal of Obstetrics \& Gynaecology, 98(3), 287-293.

7. Radunovic, N. E. B. O. J. S. A., Lockwood, C. J., Alvarez, M. A. N. U. E. L., Plecas, D. A. R. K. O., Chitkara, U. S. H. A., \& Berkowitz, R. L. (1992). The severely anemic and hydropic isoimmune fetus: changes in fetal hematocrit associated with intrauterine death. Obstetrics and gynecology, 79(3), 390-393.

8. Mari, G., Deter, R. L., Carpenter, R. L., Rahman, F., Zimmerman, R., Moise Jr, K. J., ... \& Oz, U. (2000). Noninvasive diagnosis by Doppler ultrasonography of fetal anemia due to maternal red-cell alloimmunization. New England Journal of Medicine, 342(1), 9-14.

9. Sohan, K., Carroll, S. G., Fuente, S. D. L., Soothill, P., \& Kyle, P. (2001). Analysis of outcome in hydrops fetalis in relation to gestational age at diagnosis, cause and treatment. Acta obstetricia et gynecologica Scandinavica, 80(8), 726-730.

10. Ratanasiri, T., Komwilaisak, R., Sittivech, A., Kleebkeaw, P., \& Seejorn, K. (2009). Incidence, causes and pregnancy outcomes of hydrops fetalis at Srinagarind Hospital, 1996-2005: a 10-year review. J Med Assoc Thai, 92(5), 594-599.

11. Tannirandorn, Y., \& Rodeck, C. H. (1990). 5 New approaches in the treatment of haemolytic disease of the fetus. Bailliere's clinical haematology, 3(2), 289-320.

12. Nicolaides, K. H., Clewell, W. H., Mibashan, R. S., Soothill, P. W., Rodeck, C. H., \& Campbell, S. (1988). Fetal haemoglobin measurement in the assessment of red cell isoimmunisation. The Lancet, 331(8594), 1073-1075.

13. Nicolaides, K. H., Warenski, J. C., \& Rodeck, C. H. (1985). The relationship of fetal plasma protein concentration and hemoglobin level to the development of hydrops in rhesus isoimmunization. American journal of obstetrics and gynecology, 152(3), 341-344. 